\title{
"Taking Hands"
}

\author{
by Paulette Callen
}

Sometimes I get to thinking...

I'm an ANIMAL RIGHTS ACTIVIST! and I get all full of myself, and I begin to loathe the hunters and despise the trappers... and then I get to thinking about what Paul Watson said that he'd rather take the bloodied hand of an honest seal hunter than the hand of a hypocrite, and I get to thinking...

Yes! Give me the hand of the hunter over the manicured hands of those who buy the cleaned up, bled, re-christened remains of poor dead creatures wrapped in cellophane; give me the weathered hand of the trapper over the soft, ringed hands of those who pluck

their furs off racks in carpeted muzak-infected department stores out of sight and sound of the killing and dying...

and then I get to thinking

about the time -

it wasn't so long ago -

when I petted my spaniel's head

with one hand

and ate my hamburger with the other, and about the time not so very long ago when I snuggled with cozy rectitude into the raccoon collar of my car coat, and I get to thinking... whose hand can I not take?

Ah! The vivisector's! Lowest of the low... and I get to thinking of that biology class, not so long ago,

wherein I held a great luminous green frog and stroked him till he tranced a froggy

trance right in my hand!

and I gave him up to the killers to prepare him dead

for Tuesday when I sliced him to pieces for a Bt.

Whose hand can I not take?

And still I take the medicines ground out of the labs that grind away upon the

mangled bodies of my brothers and sisters,

and I think,

Whose hand can I not take?

Then I think, surely the poachers, those who, for a few cents, kill the gorilla and cut off his hands

for ashtrays,

and what should I do -

stand before them

armed with my loathing?

or hold out my hands

and say

Here, take mine. 